\title{
Mini-Review
}

\section{On the Transfer of Nicotine from Tobacco to the Smoker. A Brief Review of Ammonia and "pH" Factors}

\author{
by \\ Michael Dixon ${ }^{1}$, Klaus Lambing ${ }^{2}$, Jeffrey I. Seeman ${ }^{3,4}$ \\ ${ }^{1}$ British American Tobacco, Globe House, 4 Temple Place, London WC2R 2PG, England \\ ${ }^{2}$ Philip Morris GmbH, Central-QA Laboratories, Fallstrasse 40, D-81369 München, Germany \\ ${ }^{3}$ Philip Morris US A, P. O. Box 26583, Richmond, Virginia 23261-6583, USA \\ ${ }^{4}$ Current address: SaddlePoint Frontiers, 12001 Bollingbrook Place, Richmond, Virginia 23236-3218, USA
}

SUMMARY

ZUSAMMENFASSUNG

\begin{abstract}
A brief review is presented of the scientific literature on the effects of ammonia compounds, when used as tobacco additives, on the smoke chemistry and bioavailablity of nicotine. The review concludes that ammonia compounds used in the manufacture of certain types of tobacco sheet materials: 1) contribute to the flavor properties of cigarette smoke, 2) do not increase the amount, rate or efficiency of nicotine transferred from tobacco to mainstream smoke (MS), 3) do not increase the percentage of nicotine in MS gas phase using the FTC/ISO (Federal Trade Commission/International Organization for Standardization) method, 4) have no influence on the determination of MS nicotine yield as measured by the FTC/ISO method, and 5) do not increase the total rate or amount of nicotine absorbed by the smoker. The review also examines the use of $p H$ as it relates to tobacco and to smoke and suggests a terminology which more accurately describes the measurement $(p H$ of aqueous extract of tobacco, $p H$ of aqueous extract of smoke, and $p H /$ electrode in smoke). Lastly, a number of research gaps in these areas are identified. [Beitr. Tabakforsch. Int. 19 (2000) 103-113]
\end{abstract}

Es wird eine kurze Übersicht über die wissenschaftliche Literatur zu den Auswirkungen von Ammoniumverbindungen als Tabakadditive auf die Rauchchemie und die Bioverfügbarkeit von Nikotin gegeben. Aus der Literatur folgt, dass Ammoniumverbindungen, die bei der Herstellung von bestimmten Arten von Tabakfolie eingesetzt werden: 1) zum Aroma des Cigarettenrauchs beitragen, 2) die Nikotinmenge sowie die Geschwindigkeit und Effizienz des Nikotinübergangs vom Tabak in den Hauptstromrauch (HSR) nicht erhöhen, 3) den nach FTC/ISO (Federal Trade Commission/International Organization for Standardization) ermittelten Nikotingehalt in der Gasphase des HSR nicht erhöhen, 4) keinen Einfluß auf den nach FTC/ISO ermittelten Nikotingehalt im HSR haben, 5) die Geschwindigkeit und die vom Raucher aufgenommene Nikotinmenge nicht erhöhen. In der Übersicht wird ebenfalls der Gebrauch der Bezeichnung $p H$ in Bezug auf Tabak und Rauch untersucht und es werden Definitionen vorgeschlagen, die die Messung präziser beschreiben ( $p H$ des wässrigen Tabakextraktes, $p H$ des 


\section{RESUME}

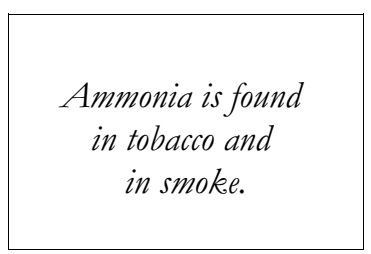

Ammonia compounds are used as flavorants and as processing aids in the manufacture of cigarettes. wässrigen Rauchextraktes und $p H /$ Elektrode im Rauch. Abschließend werden einige Forschungslücken auf diesem Gebiet aufgezeigt. [Beitr. Tabakforsch. Int. 19 (2000) 103-113]

Une brève revue de la littérature scientifique, sur les effets des composés contenant de l'ammoniac utilisés comme additifs du tabac, sur la chimie de la fumée et la biodisponibilité de la nicotine, est présentée. Cette revue aboutit à la conclusion que les composés contenant de l'ammoniac utilisés dans la fabrication de certains types de tabac reconstitué: 1) contribuent à l'arôme de la fumée de cigarettes, 2) n'augmentent pas la quantité, le taux ou l'efficacité de la nicotine transférée à partir du tabac vers la fumée du courant principal (CP), 3) n'augmentent pas la teneur en nicotine dans la phase gazeuse du CP obtenu selon la méthode FTC/ISO (Federal Trade Commission/International Organisation for Standardization), 4) n'influencent pas le rendement en nicotine du CP obtenu selon la méthode FTC/ISO et 5) n'augmentent pas le taux total ou la quantité de la nicotine absorbée par le fumeur. La revue examine également l'utilisation de la dénomination de $p H$ relative au tabac et à la fumée, et propose des définitions qui décrivent plus précisément la mesure ( $p H$ d'extrait aqueux de tabac, $p H$ d'extrait aqueux de la fumée, et $p H /$ électrode dans la fumée). Enfin quelques lacunes de recherche dans ce domaine sont identifiées.

[Beitr. Tabakforsch. Int. 19 (2000) 103-113]

\section{TOBACCO AND SMOKE CHEMISTRY}

Ammonia and ammonia-releasing compounds are natural constituents in tobacco (1-4). Because tobaccos used in cigarettes are naturally acidic, ammonia is protonated in tobacco, i.e., exists as ammonium salts of natural tobacco carboxylic acids (5), otherwise the ammonia would be lost by evaporation. Typical concentrations of ammonia in the tobacco blends of commercial American cigarettes are ca. $0.1-0.4 \%$, as measured by the soluble ammonia method $(2,6)$.

Ammonia is present in both the gas and particulate phases of tobacco smoke (7). Quantitative analysis of ammonia in tobacco and smoke has been reported in the literature for many years (8). In today's commercial cigarettes, ammonia is found in mainstream smoke (MS) in amounts of up to ca. $35 \mu \mathrm{g}$ per cigarette. A far greater amount of ammonia is found in sidestream smoke (SS); the SS:MS (mass) ratio is ca. 40-170:1 (9).

Ammonia compounds are used in the manufacture of some types of cigarettes for two reasons. First, tobacco-identical ammonia compounds such as ammonium hydroxide (i.e., an aqueous solution of ammonia) and diammonium phosphate are added as processing agents in the manufacture of some types of tobacco sheet (2, $10,11)$. Second, ammonia compounds serve as flavorants and also as flavor precursors. They can react during tobacco processing and smoking with oxygencontaining compounds, including sugars, to form flavorants $(2,12,13)$. This is analogous to the formation of important flavors during the cooking of foods.

The addition of ammonia compounds to tobacco can increase the ammonia content of mainstream smoke (14). Other tobacco blend constituents such as amino acids, proteins and inorganic nitrates can form ammonia during the smoking process and hence influence the ammonia content of mainstream smoke $(2,15,16)$. A recent study of ten commercial US cigarettes revealed a correlation between mainstream smoke ammonia yield with "tar" yield (6). This study further found that cigarettes with comparable "tar" yields had approximately equal amounts of ammonia in mainstream smoke while differing in their ammonia content in tobacco by a factor of three. This suggests that ammonia deliveries in commercial cigarettes, which appear to be correlated to total smoke delivery, are affected more by cigarette design and blend characteristics than by tobacco additives. 
Nicotine can exist in its nonprotonated and protonated forms, which have different properties.

A number of reports have discussed the potential effect of ammonia, or other bases, on the transfer of nicotine (1) to smoke (5, 17-20). It is well known that nicotine can exist in its nonprotonated or free base form 1 or as mono- or diprotonated salts, 2 or 3 . While 1 is a high boiling point liquid (bp $247^{\circ} \mathrm{C}$ ) that measurably evaporates only with heating, the protonated forms (2 or 3 ) must first dissociate, decompose or disproportionate to 1 before nicotine can be transferred to smoke $(5,21)$. In principle, adding ammonia or ammoniareleasing substances to tobacco could convert protonated nicotine to nonprotonated nicotine. However, the thermal energy provided by the burning cigarette (a function of temperature and tobacco mass) is more than sufficient to convert 2 and 3 to 1 , irrespective of the presence of ammonia $(5,21)$.<smiles>CN1CCC[C@H]1c1cccnc1</smiles>

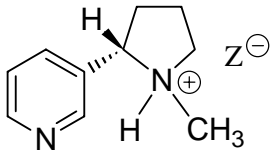

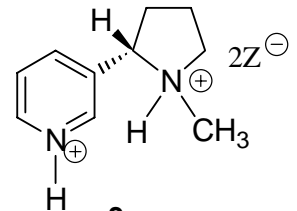

3

Based on thermal studies of nicotine salts ( 2 and 3 ) and smoke studies using covalently bonded nicotine quaternary salts ( $4 a$ and $4 b)$, nicotine and nicotine carboxylic acids, such as found in tobacco, transfer nicotine to smoke with essentially identical efficiencies $(5,21,22)$. Transfer of nicotine to mainstream smoke was recently measured for cigarettes made with the addition of seven different nicotine carboxylic acid salts and both enantiomers of nicotine to the tobacco blend. The authors concluded that the degree of thermal stability of the nicotine salts had no bearing on the efficiency of transfer of nicotine to smoke or on racemization of nicotine during smoking (23). The relative thermal stability of the nicotine ring system contributes to its efficient transfer to smoke: nicotine acid salts will primarily be converted to nonprotonated nicotine and evaporate at temperatures lower than the temperatures required to decompose the nicotine ring system or racemize its chiral center $(5,21,23)$.

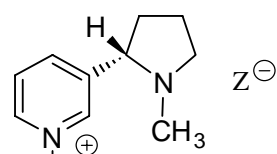

$\mathrm{R}$<smiles>[R][N+]1(C)CCC[C@@H]1c1cccnc1</smiles>

$4 b$
"pH of aqueous extracts of tobacco" and "pH of aqueous extracts of smoke" may give estimates of relative concentrations of acids and bases in tobacco and in smoke.
$4 a$

Some attention has been placed on using the measured values of $p H$ of tobacco and $p H$ of smoke to predict smoke chemistry. For example, studies have been reported using $\mathrm{pH}$ to quantify the percentages of nicotine in its three forms, 1-3 $(24,25)$. While a knowledge of the $\mathrm{pK}_{\mathrm{a}}$ values of the compounds of interest and the $\mathrm{pH}$ of the aqueous solution accurately predicts the position of acid-base equilibria of components in a dilute aqueous solution at equilibrium (the Henderson-Hasselbach equation) (25), this theory cannot be applied to either tobacco or smoke directly. Neither tobacco nor smoke is a dilute aqueous solution, and neither is at equilibrium. However, $\mathrm{pH}$ measurements may possibly provide an indication of the relative concentrations of the aqueousextractable acids and bases in tobacco and smoke.

Consider first the $p H$ of tobacco. This measurement is typically made by extracting tobacco samples with water, filtering the mixture, and measuring the $\mathrm{pH}$ of the resultant aqueous solution. Because the nomenclature $p H$ of tobacco is both ambiguous and misleading, we recommend that this experimental 


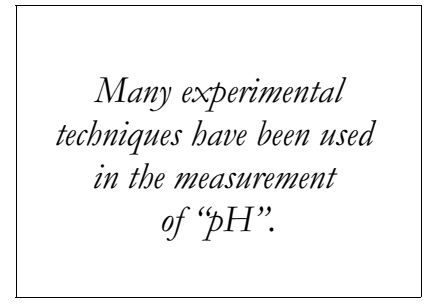

"pH/ electrode in smoke" and "pH of aqueous extract of smoke" are not predictive of the amount of ammonia in tobacco or in smoke.

Two definitions of "gas-phase nicotine" parameter be renamed the $p H$ of aqueous extract of tobacco. $\mathrm{pH}$ measurements of aqueous extracts of Bright, Burley, and Oriental tobaccos as well as of reference and commercial cigarette tobaccos over the past 40 years have typically resulted in values in the range of $5.5-6.5(5,10,26)$. The first $\mathrm{pK}$ of nicotine is ca. 8.0. Thus, nicotine in a dilute aqueous solution of $\mathrm{pH} 6.0$ will be ca. $1.5 \%$ nonprotonated 1 and $98.5 \%$ monoprotonated 2 . Thermogravimetric analysis and related studies of tobacco samples indicate that nicotine evolution is consistent with its being protonated in the tobacco matrix as nicotine volatilizes (5). Thus, one can reasonably predict that most of the nicotine in tobacco is protonated (5).

Two types of methods have been used to measure $p H$ of smoke. Many studies have reported the $\mathrm{pH}$ of aqueous extracts of FTC (or FTC-type) total particulate matter (TPM) and of (portions of) whole smoke, trapped under different conditions (27-31). While these methods have the capability of extracting water soluble substances, the trapping of MS carbon dioxide in some methods but not in others is likely to lead to method-dependent $\mathrm{pH}$ values (27). We recommend that this technique be called the $p H$ of aqueous extract of smoke.

SENSABAUGH and CUNDIFF $(32)$, and others $(24,33)$ including most recently Labstat, Inc. $(6,34)$ have reported the use of a special electrode, coated with an aqueous-based gel, inserted into the path of flowing MS. This latter method provides measurements on a puff-by-puff basis but suffers from a questionable ability to extract all water-soluble materials. Consequently, neither $p H$ of smoke nor $p H$ of an aqueous extract of smoke seem completely descriptive of this technique. We recommend the name $p H /$ electrode in smoke be used to describe this methodology.

No comprehensive study has been published to date that has examined a number of different $p H$ methodologies using MS from the same series of cigarettes. Nonetheless, any use of measured $p H$ values to quantify the actual percentage of 1-3 in tobacco smoke goes well beyond the theoretical underpinning of the Henderson-Hasselbach equation. However, all of the measurements of $p H$ of aqueous extract of smoke and $p H /$ electrode in smoke of flue-cured and US-blended style commercial cigarettes result in values in the acidic range. We therefore conclude that most of MS nicotine is protonated.

Two recent studies, one based on ten US commercial cigarettes (6) and one based on reference and test cigarettes (14) containing varied levels of ammoniaproducing compounds as additives, demonstrated that the $p H$ of smoke was not significantly affected by ammonia content in the tobacco. These two studies also demonstrated that ammonia content in smoke did not significantly affect the $p H$ of smoke as measured.

In the investigation of ten commercial cigarettes, ammonia levels in MS varied per cigarette by over 20-fold (from 1.4 to $33 \mu \mathrm{g} /$ cigarette) and differences in the $p H /$ electrode in smoke (6.00-6.35) were observed; importantly, no correlation between $p H /$ electrode in smoke and soluble (tobacco) ammonia was found (6). A weak, inverse (negative) correlation was found between $p H /$ electrode in smoke and MS ammonia.

In the second study, the control cigarette and two of the test (model) cigarettes had ammonia compounds in the reconstituted tobacco in the blend, while the other two test cigarettes had no added ammonia compounds; filler soluble ammonia ranged from $0.12 \%$ to $0.31 \%$ (dry weight basis). All five cigarettes had the same FTC "tar" yields. The ammonia levels in MS varied from 6.1 to $11.9 \mu \mathrm{g}$ per cigarette; $p H$ of aqueous extracts of smoke was between 5.3-5.4, again without any correlation of $p H$ with smoke ammonia (14). In addition, the nicotine yields were essentially the same. Thus, in these two studies, the ammonia content of MS does not appear to significantly alter the measured $p H$ of smoke.

Nicotine (and ammonia, as well as other smoke constituents) can be found in both the gas phase and particle phase of tobacco smoke (9). We note here that the term "gas-phase nicotine" can have two different definitions. 


\section{FTC method accurately quantifies nicotine in mainstream smoke.}

1) At any time and position during the smoking of a cigarette, the smoke is made up of a particulate phase and a gas - or vapor - phase. Less than $1 \%$ of the total nicotine in MS as it exits the cigarette is in the gas phase (35-37).

2) As part of the FTC/ISO methods for measuring "tar" and nicotine yields, a Cambridge filter is placed behind the cigarette (38). The nicotine that is trapped on the Cambridge filter is reported as "FTC nicotine." The nicotine not trapped on the Cambridge filter is sometimes referred to as "gas-phase nicotine".

It has recently been hypothesized (20) that the FTC method under-reports a significant percentage of the nicotine in MS, attributed to a postulated failure of the FTC method to capture gas-phase nicotine (Definition no. 2 above). Further, it was hypothesized that ammonia in smoke will increase the percentage of nicotine in the gas phase (Definitions no. 1 and/or no. 2 above) which is not trapped by the Cambridge filter pad (20).

Two studies using isotopically labeled nicotine $\left({ }^{14} \mathrm{C}\right.$ and $\left.{ }^{2} \mathrm{H}\right)$ clearly demonstrated that greater than $99 \%$ of nicotine in MS is collected on the Cambridge pad; in these studies, no nicotine in the gas phase (Definition no. 2) was observed $(39,40)$. Experimental confirmation of these results can be found in the work of BEVAN, ELLIS and their respective co-workers. BEVAN found Cambridge filter efficiencies of $>99 \%$ for nicotine in the smoke of commercial flue-cured cigarettes having acidic MS as well as for dark air-cured cigarettes having basic smoke (Reported on page 4-5 of Ref. 9). Recently, ELLIS et al. examined a set of cigarettes with different amounts of smoke ammonia. The trapping efficiency of the Cambridge filter for MS nicotine was not only found to be $>99 \%$ but also independent of the ammonia content in MS $(14,41)$.

\section{NICOTINE BIOAVAILABILITY}

Nicotine bioavailablity to the smoker will now be examined. In addition, the potential effect of ammonia-releasing compounds in tobacco on the amount and rate of nicotine absorbed by the smoker will be evaluated. It is necessary to consider the dynamic nature of smoke that manifests itself, in part, by the non-equilibrium partitioning of smoke components between the gas and particulate phases.

Gas-phase nicotine deposits primarily in the mouth and upper respiratory tract. We know this because "nicotine vapor inhalers", a source of gas-phase nicotine, are known to result in nicotine being found primarily in the oral cavity, esophagus, and stomach in humans (42-45). Inhalation of nicotine vapor results in little deposition in the lung. Further, these and related published reports, including human smoking studies, demonstrate that nicotine transfers poorly from the mouth to the blood, with a slow uptake to the systemic circulation and also without any indication of a spike or "bolus" concentration $(43,46-51)$.

Greater than $99 \%$ of the nicotine in MS is in the particulate phase as the smoke exits the cigarette $(35,37,52)$. MS particles are generally small (mass median diameters $<0.5 \mu \mathrm{m})(53,54)$ and these travel to the lung $(55,56)$.

At least two fundamentally different mechanisms account for nicotine's highly efficient deposition in the respiratory system. First, smoke particles will be deposited onto the surfaces of the airways within the lung by inertial impaction, Brownian diffusion, and gravitational sedimentation of the smoke particles $(55,57)$. Second, as the concentrated bolus of smoke becomes diluted with air in the mouth and respiratory system, this dilution will result in volatiles and semi-volatiles, including nicotine, evaporating from the smoke particles and depositing by diffusion onto the respiratory surfaces (36).

FROST et al. reported that $>90 \%$ of the nicotine and ca. $50 \%$ of the solanesol (5) in MS was retained within the respiratory system following a $500 \mathrm{~mL}$ 
inhalation (51). As solanesol is considered to be a non-volatile component of smoke, it must deposit only by a particle-deposition mechanism. Thus, FROST et al. concluded that the relatively higher respiratory retention of nicotine was evidence for the evaporation of nicotine from smoke particles being a significant deposition mechanism (51).

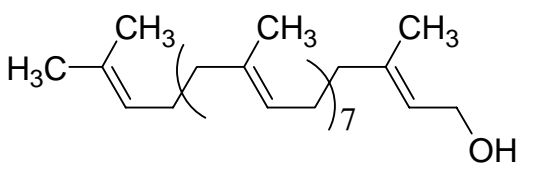

5

To the extent that ammonia in smoke influences the amount or rate of evaporation of nicotine from particles to the gas phase, a number of conclusions seem evident. (a) For ammonia to have any effect on nicotine evaporation from a particle, the ammonia must be in that particle $(37,58)$; (b) ammonia itself has a very high vapor pressure and would evaporate from the particles faster than the nicotine (59); (c) because of its very high water solubility, gas-phase ammonia entering the mouth will rapidly deposit primarily there $(60,61)$; (d) smoke particles entering the lung are likely to be ammonia-depleted relative to nicotine, due to the greater rate of evaporation of ammonia from the particles as they travel to the lung; (e) once in the lung, any remaining ammonia will also evaporate faster from smoke particles than nicotine. Taking these factors together, ammonia is unlikely to have any major influence on the evaporation of nicotine from smoke particles within the lung. Ammonia's influence, if any, will be early in the history of the aerosol, in the mouth and upper respiratory tract, where nicotine absorption is slower and has ca. 50\% absorption efficiency compared with absorption in the lung which is fast and occurs with $80-90 \%$ efficiency (46). These experimental observations indicate that the presence of ammonia in tobacco smoke does not ultimately increase the amount or rate of nicotine absorbed in the lung.

A number of comprehensive reviews have concluded that, when tobacco smoke reaches the small airways and alveoli of the lung, nicotine is rapidly absorbed into the pulmonary circulation and that smoke $p H$ has no effect on either the amount or rate of nicotine absorption in the lung; the nicotine is rapidly absorbed independent of $\mathrm{pH}$ of the smoke $(49,62-65)$. These conclusions are based, in part, on considering the amount of nicotine per puff and the buffering capacity of the lung. Each MS puff contains only a small amount of nicotine (ca. $0.01-0.1 \mathrm{mg}$ ). Further, nicotine reaching the lung will be distributed over the lung's extensive surface area. These factors ensure that the lung's significant buffering capacity at $\mathrm{pH} 7.4$ will not be overcome.

Thus, nicotine distributed in the fluids lining the surface of the lung will always exist at a 20:80 ratio of "nonprotonated" 1 to "protonated" nicotine 2 regardless of the form(s) in which it enters the lungs. Only nonprotonated nicotine is nonionized and can move readily across the lung membrane (see Figure 1). However, very rapid acid-base interconversion in the buffered environment maintains the 20:80 ratio of "nonprotonated" 1 to "protonated" nicotine 2 , and the nicotine can thus transfer rapidly to the plasma (see Figure 1).

The physiological pH of blood is also $\mathrm{pH} 7.4$, which means that the same 20:80 ratio of "nonprotonated" to "protonated" nicotine exists in the bloodstream (25). This 20:80 "nonprotonated" to "protonated" ratio for nicotine reaching the blood-brain barrier cannot be changed, regardless of the form in which nicotine enters the lung. In other words, even if nicotine existed in cigarette smoke as $100 \%$ "nonprotonated" nicotine, it would be at the same ratio (20 to 80 : "nonprotonated" to "protonated") at the surface of the lung, in the bloodstream, and as it reaches the blood-brain barrier $(49,66)$.

Recent work by ROSE et al. indicates that transfer of nicotine from the lung to 


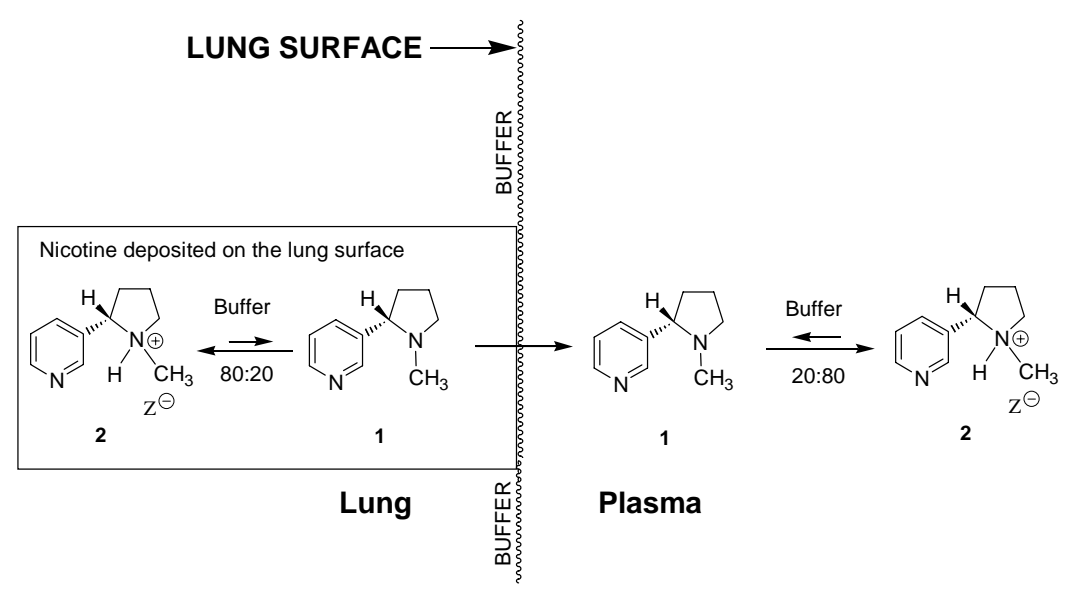

Full mechanistic details of nicotine's transfer from lung to plasma are still to be experimentally determined.
Conclusions presented are, and must be, supported by experimentation and scientific data.
Figure 1.

A schematic of the kinetic system involving nicotine and its monoprotonated salt in two buffered ( $\mathrm{pH} 7.4$ ) systems, at the lung surface and in the plasma. The rapid interconversion between 1 and 2 ensures that nicotine can transfer to the plasma.

blood, while rapid, does not result in a large spike of nicotine in arterial blood (67). These results appear to be inconsistent with the previously postulated (47) "bolus effect". ROSE et al. suggested that lung tissue uptake of nicotine might slow the rate of nicotine into the systemic circulation, as found for other alkaloids, perhaps involving alkaloid binding by lung tissue (67). As acid-base reactions are extremely rapid, especially in a buffered system, the kinetics and mechanism(s) involved in alkaloid lung absorption are not likely to be controlled by ammonia initially present in MS particles as they exit the cigarette.

Let us compare mouth absorption to lung absorption. An increased amount of nonprotonated nicotine in MS could shift the site of absorption of some nicotine from the small airway/alveolar region of the lung to the mouth/upper airway region. At a constant amount of nicotine in MS, an increased proportion of gas-phase nicotine (Definition no. 1) may result in an overall reduction (rather than an increase) in the overall amount and rate of nicotine absorption and flow to the central nervous system.

The available experimental data to date, covering decades of published literature, indicate that ammonia compounds used in the manufacture of commercial cigarettes:

- Serve as processing agents in the manufacture of certain types of tobacco sheet.

- Contribute to the flavor properties of cigarette smoke.

- Do not increase the amount or rate of nicotine transferred from tobacco to smoke.

- Have no influence on the determination of MS nicotine yield when the FTC/ISO method is used (and the FTC/ISO method captures $>99 \%$ of MS nicotine).

- Do not increase the amount or total rate of nicotine absorbed by the smoker.

- Do not increase the amount and total rate of nicotine uptake to the central nervous system.

- Do not appear to affect the $p H /$ electrode in smoke and/or $p H$ of aqueous extracts of smoke measurements under commercial-use levels.

In addition, there is no experimental evidence that $p H$ of aqueous extracts of tobacco or smoke or $p H$ / electrode in smoke have meaningful quantitative predictive value for the percentage of nonprotonated nicotine in MS or for the percentage of nicotine in the gas phase of MS. 
Future research will increase our understanding and knowledge of nicotine's transfer to smoke and bioavailability.
While these conclusions are based on substantial and consistent scientific data derived from many studies worldwide, research gaps still do exist. We are aware that laboratories around the world are working to fill these gaps. For example, no studies have been reported in which cigarettes having different amounts of ammonia in tobacco, or in smoke, have been smoked and either plasma nicotine or brain nicotine levels determined. The detailed mechanisms, kinetics, and partitioning of all routes of nicotine absorption in the smoker are not fully understood. Neither experimental nor theoretical studies have been published on the relative rates of evaporation of ammonia, nicotine, or other bases or acids from either tobacco smoke particles or from particles from related synthetic aerosols. The formation and transfer to smoke from presumed ammonia precursors (amino acids, proteins or the ammonia compounds added during manufacture) have not been experimentally quantified. We hope and expect to see the results of many new studies in the near future.

Acknowledgments: We thank Drs. Richard Baker, Cathy Ellis, Ruth Dempsey, Jay A Fournier, Lutz Mueller, John B. Paine III, Thomas Perfetti, Edward B. Sanders, Roger Walk, and three unidentified reviewers for helpful comments and Dr. Perfetti for allowing us to cite unpublished material. We also thank Alan Goldsmith and Kathy Mitchell for technical assistance.

\section{REFERENCES}

1. Akehurst, B.C.: Tobacco; $2^{\text {nd }}$ ed., Longmans, London, 1981.

2. Leffingwell, J.C.: Basic chemical constituents of tobacco leaf and differences among tobacco types; in: Tobacco: production, chemistry and technology, edited by D.L. Davis and M.T. Nielsen, Blackwell Science Ltd, Oxford, 1999, pp. 265-84.

3. Stedman, R.L.: The chemical composition of tobacco and tobacco smoke; Chem. Rev. 68 (1968) 153-207.

4. Shmuk, A.A.: The chemistry and technology of tobacco; Pioschepromizdat, Moskow, 1953.

5. Seeman, J.I., J.A Fournier, J.B.Paine III and B.E. Waymack: Thermal properties of nonprotonated and protonated nicotine. The use of thermolysis as a model for smoke formation chemistry; J. Agric. Food Chem. 47 (1999) 5133-5145.

6. Rickert, W.S.: Partial characterization of 10 'common' brands of American cigarettes; Project Report prepared for the Massachusetts Department of Public Health, Labstat, Inc., Kitchener, ON, January 30, 1997.

7. Brunnemann, K.D., and D. Hoffmann: Gas chromatographic determination of ammonia in cigarette and cigar smoke; J. Chromat. Sci. 13 (1975) 159-163.

8. Sloan, C.H., and G.P. Morie: Determination of ammonia in tobacco and tobacco smoke with an ammonia electrode; Anal. Chim. Acta. 69 (1974) 243-247.

9. Baker, R.B.: Smoke chemistry; in: Tobacco. Production, chemistry and technology, edited by D.L. Davis and M.T. Nielsen, Blackwell Science, Oxford, 1999, pp. 398-439.

10. Browne, C.L.: The design of cigarettes; Hoechst Celanese Corporation, Charlotte, NC, 1990.

11. Hind, J.D., and R.B. Seligman: Method of preparing a reconstituted tobacco sheet employing a pectin adhesive; Philip Morris, US Patent 3,420,241, January 7, 1969.

12. Leffingwell, J.C.: Nitrogen components of leaf and their relationship to smoking quality and aroma; Rec. Adv. Tob. Sci. 2 (1976) 1-31. 
13. Leffingwell, J.C., and D. Leffingwell: Chemical and sensory aspects of tobacco flavor - an overview; Rec. Adv. Tob. Sci.7 (1981) 169-217.

14. Ellis, C.L., R.H. Cox, C.H. Callicutt, S.W. Laffoon, K.F. Podraza, J.I. Seeman, R.D. Kinser, D.E. Farthing, and F.H. Hsu: The effect of ingredients added to tobacco in a commercial Marlboro Lights cigarette on FTC nicotine yield, "smoke $\mathrm{pH}$ " and Cambridge filter trapping efficiency; CORESTA Smoke and Technology Meeting, Innsbruck/ Austria, September 5-8, CORESTA Bull. No. 3, 1999, p 108.

15. Johnson, W.R., R.W. Hale, S.C. Clough, and P.H. Chen: Chemistry of the conversion of nitrate nitrogen to smoke products; Nature 243 (1973) 223-225.

16. Osdene, T.S.: Reaction mechanisms in the burning cigarette; in: The recent chemistry of natural products, including tobacco, edited by N.J. Fina, Philip Morris, Richmond, VA, 1975, pp. 41-60.

17. Kessler, D.A.: The control and manipulation of nicotine in cigarettes; Subcommittee on Health and the Environment Committee on Energy and Commerce, U.S. House of Representatives, July 21, 1994.

18. Kessler, D.A., P.S. Barnett, A.M. Witt, M.R. Zeller, J.R. Mande, and W.B. Schultz: The legal and scientific basis for FDA's assertion of jurisdiction over cigarettes and smokeless tobacco; J. Am. Med. Assoc. 227 (1997) 405-409.

19. Hurt, R.D., and C.R. Robertson: Prying open the door to the tobacco industry's secrets about nicotine; J. Am. Med. Assoc. 280 (1998) $1173-1181$.

20. Bates, C., M. Jarvis, and G. Connolly: Tobacco additives - cigarette engineering and nicotine addiction; Action on Smoking and Health Web Site, http://www.ash.org.uk/papers/ additives.html, July 14, 1999.

21. Fournier, J.A., J.B. Paine III, J.I. Seeman, D.A. Armstrong, and X. Chen: Thermal mechanisms for the transfer of amines, including nicotine, to the gas phase and aerosols; submitted for publication.

22. Obi, Y., Y. Shimada, K. Takahashi, K. Nishida, T. Kisaka: Reaction products of nicotine with ethylene oxide and their pyrolysis; Tob. Sci. 12 (1968) 70-74.

23. Perfetti, T., A.B. Norman, B.M. Gordon, W.M. Coleman III, G.M. Dull, and W.C. Miller: The transfer of nicotine from nicotine salts to mainstream smoke; Beitr. Tabakforsch. Int., accepted for publication.

24. Brunnemann, K.D., and D. Hoffmann: The $\mathrm{pH}$ of tobacco smoke; Food Cosmet. Toxicol. 12 (1974) 115-124.

25. Morie, G.P.: Fraction of protonated and unprotonated nicotine in tobacco smoke at various $\mathrm{pH}$ values; Tob. Sci. 16 (1972) 167.

26. Wolf, F.A.: Aromatic or Oriental tobaccos; Duke University Press, Durham, NC, 1962.

27. Dong, J.-Z., J.N. Glass, T. Thompson, B.F. Price, J.H. Lauterbach, and S.C. Moldoveanu: A simple technique for determining the $\mathrm{pH}$ of whole cigarette smoke; Beitr. Tabakforsch. Int. 19 (2000) 33-48.

28. Elson, L.A., T.E. Betts, and R.D. Passy: The sugar content and the $\mathrm{pH}$ of the smoke of cigarette, cigar and pipe tobaccos in relation to lung cancer; Int. J. Cancer 9 (1972) 666-675.

29. Grob, K.: Die Bestimmung des $\mathrm{pH}-$ Wertes und der Pufferungkapazität des Cigarettenrauches als Routine-Methode; Beitr. Tabakforsch. 1 (1961) 97-100.

30. Callicutt, E.H., J.M. Garman, J.M. Shackleford, and K. Walker: pH determination of an aqueous solution of mainstream cigarette smoke; $52^{\text {nd }}$ Tobacco Science Research Conference, Atlanta, Georgia, 1998, Program Booklet and Abstracts, Vol. 52, no. 8, p. 19.

31. Harris, J.L., and L.E. Hayes: A method for measuring the $\mathrm{pH}$ value of whole smoke; Tob. Sci. 21 (1977) 58-60.

32. Sensabaugh, A.J., and R.H. Cundiff: A new technique for determining the 
pH of whole tobacco smoke; Tob. Sci. 11 (1967) 25-30.

33. Hoffmann, D., G. Rathkamp, K.D. Brunnemann, and E.L. Wynder: On the profile analysis of tobacco smoke; Sci. Total Environ. 2 (1973) 157-171.

34. Rickert, W.S., J.C. Robinson, and B. Rogers: A comparison of tar, carbon monoxide, and $\mathrm{pH}$ levels in smoke from marihuana and tobacco cigarettes; Can. J. Public Health 73 (1982) 386-391.

35. Lewis, D.A., I. Colbeck, and D.C. Mariner: Diffusion of mainstream tobacco smoke and its effects upon the evaporation and diffusion of nicotine; Anal. Chem. 66 (1994) 3525-3527.

36. Mariner, D.C., and B.E. Frost.: Determination of nicotine evaporation from mainstream smoke using denuder tubes; Proceedings of the CORESTA Congress, October 1998, Brighton, England, pp. 206-210.

37. Pankow, J.F., B.T. Mader, L.M. Isabelle, W. Luo, A. Pavlick, and C. Liang: Conversion of nicotine in tobacco smoke to its volatile and available free-base form through the action of gaseous ammonia; Environ. Sci. Technol. 31 (1997) 2429-2433.

38. Rodgman, A.: FTC "tar" and nicotine in mainstream smoke: a retrospective; Rec. Adv. Tob. Sci. 23 (1997) 5-74.

39. Houseman, T.H.: Studies of cigarette smoke transfer using radioisotopically labelled tobacco constituents. Part II: The transference of radioisotopically labelled nicotine to cigarette smoke; Beitr. Tabakforsch. 7 (1973) $142-147$.

40. Stevens, N.A., and M.F. Borgerding: GC-AED studies of nicotine fate in a burning cigarette; Anal. Chem. 72 (1999) 2179-2185.

41. Kinser, R.D., F.H. Hsu, D.E. Farthing, L.D. Johnson, and C.L. Ellis: Nicotine collection efficiency in the FTC nicotine method; $53^{\text {rd }}$ Tobacco Science Research Conference, Montreal, Canada, 1999, Program Booklet and Abstracts, Vol. 53, no. 46, p. 45.

42. Lunell, E., L. Molander, K. Ekberg, and J. Wahren: Site of nicotine absorption from a vapour inhaler - comparison with cigarette smoking; Eur. J. Clin. Pharmacol. 55 (2000) 737-741.

43. Lunell, E., M. Bergstrom, G. Antoni, B. Langstrom, and A. Nordbert: Nicotine deposition and body distribution from a nicotine inhaler and a cigarette studied with positron emission tomography; Clin. Pharmacol. Ther. (1996) 593-594.

44. Bergstrom, M., A. Nordberg, E. Lunell, G. Antoni, and B. Langstrom: Regional deposition of inhaled ${ }^{11} \mathrm{C}$-nicotine vapor in the human airway as visualized by position emission tomography; Clin. Pharmacol. Ther. 57 (1995) 309-317.

45. Molander, L., E. Lunell, S.-B. Andersson, and F. Kuylenstierna: Dose released and absolute bioavailability of nicotine from a nicotine vapor inhaler; Clin. Pharmacol. Ther. 59 (1996) 394-400.

46. Schuh, K.J., L.M. Schuh, J.E. Henningfield, and M.L. Stitzer: Nicotine nasal spray and vapor inhaler: abuse liability assessment; Psychopharmacology 130 (1997) 352-361.

47. Russell, M.A.H., and C. Feyerabend: Cigarette smoking: a dependence on high-nicotine boli; Drug Metabolism Reviews 8 (1978) 29-57.

48. Russell, M.A.H., M.J. Jarvis, G. Sutherland, and C. Feyerabend: Nicotine replacement in smoking cessation; J. Amer. Med. Assoc. 257 (1987) 3262-3265.

49. Benowitz, N.L.: Nicotine pharmacology and addiction; in: Nicotine safety and toxicity, edited by N.L. Benowitz, Oxford University Press, New York, 1998, pp. 3-16.

50. Gori, G.B., N.L. Benowitz, and C.J. Lynch: Mouth versus deep airways absorption of nicotine in cigarette smokers; Pharm. Biochem. Behav. 25 (1986) 1181-1184.

51. Frost, B.E., D.C. Mariner, and N.M. Sinclair: Factors relating to nicotine 
physio-chemistry and retention in human smokers; CORESTA Congress, Brighton, England, 1998, pp. 211-218.

52. Lewis, D.A., I. Colbeck, and D.C. Mariner: Diffusion of mainstream tobacco smoke and its effects upon the evaporation and diffusion of nicotine; J. Aerosol Sci. 26 (1994) 841-846.

53. Ingebrethsen, B.: Aerosol studies of cigarette smoke; Rec. Adv. Tob. Sci. 12 (1986) 54-142.

54. McRae, D.D.: The physical and chemical nature of tobacco smoke; Rec. Adv. Tob. Sci. 16 (1990) 233-323.

55. Prodi, V. and A. Mularoni: Particulate deposition in smoking; in: Smoking and the lung; edited by G. Cumming and G. Bonsignore, Plenum Press, New York and London, 1984, pp. 249-285.

56. Dalhamn, T., M.-L. Edfors, and R. Rylander: Mouth absorption of various compounds in cigarette smoke; Arch. Environ. Health 16 (1968) 831-835.

57. Newman, S.P.: Aerosol deposition characteristics in inhalation therapy; Chest 88 (1985) 152S-160S.

58. Liang, C. and J.F. Pankow: Gas/particle partitioning of organic compounds to environmental smoke: Partition coefficient measurments by desorption and comparison to urban particulate matter; Environ. Sci. Technol. 30 (1996) 2800-2805.

59. Trowbridge, C.G., J.P. Snyder, J.I. Seeman, and P.J. Lipowicz: Simulation of volatile loss from tobacco smoke using the aqueous system ammonia, acetic acid, and nicotine; submitted for publication.

60. Egle, J.: Retention of inhaled acetone and ammonia in the dog; Am. Ind. Hyg. Assoc. J. 34 (1973) 533-539.

61. Diller, W.F.: Acute irritant gas inhalation - classification and pathophysiology; Zentralbl. Arbeitsmed. Arbeitsschutz Ergon. 47 (1997) 96-100.

62. Benowitz, N.L., H. Porchet, P. Jacob III: Nicotine dependence and tolerance in man: pharmacokinetic and pharmacodynamic investigations; in: Progress in brain research, Vol. 79, edited by A. Nordberg, K. Fuse, B. Holmstedt, and A. Sundwall, Elsevier Science Publishers, B.V., 1989, pp. 279-287.

63. Schievelbein, H.: Nicotine, resorption and fate; Pharmacol. Ther. 18 (1982) 233-248.

64. Slade, J.: Nicotine delivery devices; in: Nicotine addiction: principles and management, Vol. 4; edited by C.T. Orleans and J. Slade, Oxford University Press, Oxford, 1993 pp. 3-23.

65. Gourley, S.G., J.J. and McNeil: Antismoking products; Med. J. Aust. 153 (1990) 699-707.

66. Benet, L.Z., D.L. Kroetz, and L.B. Sheiner: Pharmacokinetics; in: Goodman and Gilman's the pharmacological basis of therapeutics, $9^{\text {th }}$ ed., edited by J.G. Hardman and L-.E. Limbird, McGraw-Hill, New York, 1996, pp. 3-28.

67. Rose, J.E., F.M. Behm, E.C. Westman, and R.E. Coleman: Arerial nicotine kinetics during cigarette smoking and intravenous nicotine administration: implications for addiction; Drug Alcohol Dependence 56 (1999) 99-107.

Addresses for correspondence:

Mike Dixon

British American Tobacco

Globe House, 4 Temple Place

London WC2R 2PG

England
Jeffrey I. Seeman

SaddlePoint Frontiers

12001 Bollingbrook Place

Richmond, Virginia 23236

USA 